\title{
Biological Studies on Free Endotoxin and a Non-toxic Material from Culture Supernatant fluids of Escherichia coli $078 \mathrm{~K} 80$
}

\author{
By M. J. CRUTCHLEY, D. G. MARSH AND J. CAMERON \\ Wellcome Research Laboratories, Beckenham, Kent
}

(Accepted for publication I8 August 1967)

\begin{abstract}
SUMMARY
A description is given of the biological properties of two substances produced extracellularly by a strain of Escherichia coli $078 \mathrm{~K} 80$, grown in aerated liquid culture. One of the materials was of high molecular weight and possessed the properties of endotoxin extracted from whole organisms by chemical methods. In mice this material was toxic, induced non-specific resistance to infection with Salmonella typhi, necrotized Sacroma I80, and elicited the local and general Shwartzman reactions. In rabbits it was strongly pyrogenic, dermonecrotic, and induced formation of precipitating antibodies. Heat, chemicals and enzymes did not affect its toxicity, but acid hydrolysis rendered it non-toxic. We have called this substance 'free endotoxin'. The other material was of lower molecular weight and apart from inducing nonspecific resistance to infection with $S$. typhi in mice, it had none of the properties of the endotoxin.
\end{abstract}

\section{INTRODUCTION}

Endotoxin can be extracted from Gram-negative organisms by simple but biologically drastic procedures. These include extraction with trichloroacetic acid at $4^{\circ}$ (Boivin \& Mesrobeanu, 1933), with aqueous phenol at $65^{-68^{\circ}}$ (Westphal, Lüderitz, Eichenberger \& Keiderling, 1952) with aqueous ether at 6-1 $2^{\circ}$ (Ribi, Haskins, Landy \& Milner, I96I) and with water at $80^{\circ}$ (Roberts, 1966). Such chemically-extracted endotoxins are toxic, pyrogenic, provoke non-specific resistance to infection, cause dermal and tumour necrosis and elicit the local and general Shwartzman reactions.

The term 'free endotoxin' (Crutchley, Marsh \& Cameron, 1967), was introduced to describe material found free in aerated liquid cultures of several species of Gramnegative bacteria and possessing the properties of chemically-extracted endotoxin. Treatment of the supernatant fluids of such cultures with ammonium sulphate yielded a precipitate which, after purification on diethylaminoethyl cellulose and Sephadex G-I00 was found to contain two main fractions, one indistinguishable from endotoxin and the other a lower molecular weight non-toxic material which lacked most of the biological properties of endotoxin. This latter fraction we have tentatively identified (Marsh \& Crutchley, 1967) as native hapten, or as it is now called, native protoplasmic polysaccharide (Rudbach et al. 1967). The present paper describes the biological properties and serological relationships of these two fractions: free endotoxin and the non-toxic material from culture supernatants of Escherichia coli $078 \mathrm{~K} 80$. 


\section{METHODS}

Organisms. Most of the experiments were done with a strain of Escherichia coli serotype $078 \mathrm{~K} 80$. Other serotypes of $E$. coli and strains of Pasteurella multocida, Serratia marcescens, Vibrio cholerae, and Salmonella typhi were also used. All these organisms are kept as freeze dried cultures in the Culture Collection of the Wellcome Research Laboratories. For everyday use strains were maintained on Dorset's egg medium. Concentrations of suspensions of organisms were measured by using Brown's Opacity Tubes (Burroughs Wellcome \& Co.) or a Hilger spectrophotometer (model H810.30I).

Bacterial suspension (equivalent to $10 \cdot 7 \mathrm{~g}$. bacteria/1.)

1. Centrifugation

2. Sterilization (Seitz filtration)

Filtrate (1 l l.)

1. Sat. $\left(\mathrm{NH}_{4}\right)_{2} \mathrm{SO}_{4}, 6$ days at $4^{\circ}$

2. Ppt. dialysed against water

3. Centrifugation

Crude endotoxin I (solution)

1. $\left(\mathrm{NH}_{4}\right)_{2} \mathrm{SO}_{4}\left(65 \mathrm{~g} . / 100 \mathrm{ml}\right.$.), 1 day at $4^{\circ}$

2. Ppt. dialysed against water

3. Centrifugation

$\checkmark$ 4. Freeze-drying of supernatant fluid

Crude endotoxin II (120 mg.)

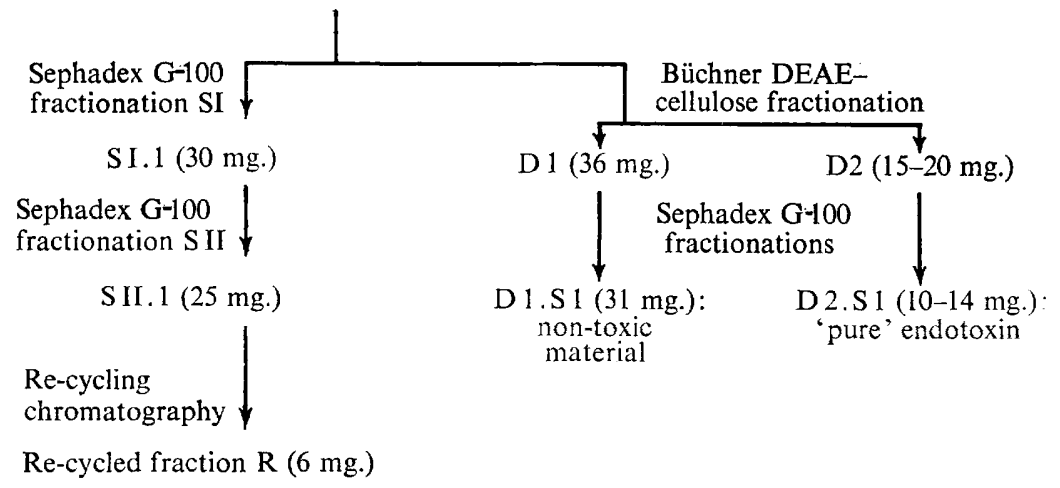

Fig. I. The preparation and purification of endotoxin and non-toxic fractions from Escherichia coli $078 \mathrm{~K} 80$. Yields of freeze-dried salt-free fractions per litre of sterile culture fluid are given in brackets after the appropriate fractions (from Marsh \& Crutchley, 1967).

Medium. The casein sucrose yeast-extract medium used (D. C. Edwards, unpublished) was described previously (Marsh \& Crutchley, 1967); it will be referred to as casein sucrose.

Growth of Escherichia coli $078 \mathrm{~K} 80$ and isolation of material from culture fluids. This was described previously (Marsh \& Crutchley, 1967). A flow diagram for the isolation of free endotoxin and non-toxic material is shown in Fig. I.

Growth of organisms. Escherichia coli serotypes other than $078 \mathrm{~K} 80$ and other 
Gram-negative bacteria were grown in casein sucrose medium for $24 \mathrm{hr}$ at $37^{\circ}$ in $250 \mathrm{ml}$ conical flasks shaken rapidly to provide aeration. Seitz-filtered cell-free culture fluids were tested as such, or as crude ammonium sulphate precipitates prepared as in the first stages of Fig. I.

Preparation of endotoxin from organisms. Chemically-extracted endotoxin was prepared from bacteria grown on casein sucrose medium solidified with agar. The extraction methods of Westphal et al. (1952), and of Ribi et al. (196I) were used.

\section{Biological tests}

W-Swiss mice were used throughout. The rabbits were of miscellaneous breeds.

Mouse lethality. This was determined in mice $(20 \mathrm{~g}$.) by the method of Haskins, Landy, Milner \& Ribi (I961). LD 50 values were calculated by the method of Reed \& Muench (1938).

Non-specific resistance to infection. Groups of mice ( $13-15$ g.) 'were injected intraperitoneally with increasing doses of the different preparations under test. Twentyfour hr later they were challenged by the same route with approximately $3 \mathrm{LD} 50$ doses of Salmonella typhi TY 2 in saline (Rowley, I955). ED 50 values were calculated by the method of Haskins et al. (I96I).

Pyrogenicity in rabbits. The method of Haskins et al. (I96I) was used.

Tumour necrosis. The method of Haskins et al. (1961) was used, but with Sarcoma I 80 instead of Sarcoma 37. Tumours were sectioned and examined visually for necrosis. TD 50 values were not measured.

\section{Shwartzman reactions}

(a) Local. Groups of five mice were injected subcutaneously with endotoxin, I8 hr later an intravenous challenge of endotoxin was given and the skin reactions read after $8 \mathrm{hr}$ (Homma, I952).

(b) General. Groups of four mice were given intravenous injections of increasing different amounts of endotoxin; 6-8 hr later the members of each group were challenged intravenously with the same amount of endotoxin as they had received initially. Shock, the presence of kidney damage, and deaths were recorded.

\section{Serological relationships of fractions}

These were examined in I \% agar plates (Oxoid, Ionagar No. 2), containing $0.5 \%$ phenol as a preservative, by Ouchterlony (1949) double-diffusion technique. Antisera were prepared in horses and rabbits by the intravenous injection of formalin-killed cells of Escherichia coli $078 \mathrm{~K} 80$. In addition, antisera against both the crude endotoxin II and the non-toxic material were prepared in rabbits by injecting them subcutaneously with the substances incorporated in an oil emulsion. Precipitin lines were allowed to develop for $72 \mathrm{hr}$ at room temperature and the diffusion patterns photographed, with dark field illumination.

\section{RESULTS}

The injection of endotoxin into guinea pigs causes hypothermia and diarrhoea (Olitzki, Avinery \& Koch, I942). Similar effects were noted when sterile culture fluids of Gram-negative bacteria, grown in aerated casein sucrose medium, were injected parenterally into mice. Rectal temperatures of these animals fell from about $\mathrm{IOI}^{\circ} \mathrm{F}$ 
$\left(38.5^{\circ} \mathrm{C}\right)$ to below $88^{\circ} \mathrm{F}\left(3 \mathrm{I}{ }^{\circ} \mathrm{C}\right)$. Severe diarrhoea started IO-I $5 \mathrm{~min}$. after injection. The body temperatures remained low for as long as $\mathrm{I} 2 \mathrm{hr}$, whereas the diarrhoea lasted for only $2 \mathrm{hr}$. These findings suggested that culture fluids from aerated cultures contained endotoxin which we propose to call 'free endotoxin', to distinguish it from material extracted from whole bacteria by chemical methods (Crutchley et al. 1967).

Free endotoxin was found in culture fluids of Vibrio cholerae, Vibrio el Tor, Salmonella typhi, Escherichia coli, and Serratia marcescens. These all grew to a population density of about ${ }^{1} 0^{11}$ organisms $/ \mathrm{ml}$. in aerated casein sucrose medium. Pasteurella multicoda also produced free endotoxin but had special growth requirements and only grew to ${ }^{10}{ }^{10}$ organisms $/ \mathrm{ml}$; ; little free endotoxin was found in static cultures of these organisms grown in the same media, where growth reached about $10^{9}$ organisms $/ \mathrm{ml}$.

In addition to free endotoxin, non-toxic material of lower molecular weight was present in culture fluids of Escherichia coli serotype 078 K 80 (Marsh \& Crutchley, 1967). This substance was similar to native hapten described by Anacker et al. (1964) or as it is now called, native protoplasmic polysaccharide (Rudbach et al. 1967). This had none of the properties of endotoxin except its ability to induce non-specific resistance to Salmonella typhi infection in mice.

Origin of free endotoxin and non-toxic material. The presence of these materials in aerated culture fluids suggested that they were released by the lysis of the organisms since it is widely held that endotoxin is a cell-wall constituent of Gram-negative bacteria. We have prepared phenol + water extracts from Escherichia coli $078 \mathrm{~K} 80$ organisms grown in aerated casein sucrose medium and on the same medium solidified with agar, and found the same amounts of endotoxin in both. However, the supernatant fluid from the liquid aerated culture contained, in addition, as much endotoxin again as could be extracted from the bacteria. This result suggested that free endotoxin might arise from metabolic overproduction during aerated growth rather than by the lysis of the bacteria.

\section{Biological properties of endotoxin and the non-toxic material}

All the materials tested were from culture fluids of Escherichia coli serotype $078 \mathrm{~K} 80$ grown in aerated casein sucrose medium. Preparation of free endotoxin and the nontoxic fraction was described by Marsh \& Crutchley (1967) and the nomenclature is that used in Fig. I.

Lethality of free endotoxin, chemically-extracted endotoxin and non-toxic material. LD 50 values for the mouse are shown in Table I. Purified free endotoxin (D2SI) was as toxic as chemically-extracted endotoxin, and the fraction DISI was non-toxic. The latter was, moreover, non-toxic for guinea-pigs even at a dose of $10 \mathrm{mg}$./animal. The toxicities of fractions S I . I and R indicated that free endotoxin was removed during chromatography of crude material on Sephadex G-100 and that the non-toxic material had accumulated.

Non-specific resistance to infection. All endotoxin samples elicited this phenomenon so characteristic of endotoxin. The non-toxic material was also effective. ED 50 values are shown in Table I.

Pyrogenicity of rabbits. The FI 40 values (amounts of material giving an area of $40 \mathrm{~cm}^{2}$ under a fever curve) are shown in Table $\mathrm{I}$.

Dermal and tumour necrosis. Severe lesions were caused in rabbits injected subcutaneously with either free or chemically-extracted endotoxin. They arose 2-3 days 
after the injection of Io $\mu \mathrm{g}$. endotoxin. No reaction followed repeated injections of a I mg. dose of the non-toxic material.

All endotoxin preparations caused necrosis of Sarcoma 180 in mice. A dose of I $\mu \mathrm{g}$. free endotoxin/mouse induced necrosis; on the other hand, $600 \mu \mathrm{g}$. of the nontoxic material was inactive. Shear endotoxic lipopolysaccharide prepared from culture fluids of Serratia marcescens and known to cause tumour necrosis, was used as a control preparation (Shear \& Turner, 1943).

Table I. Some biological properties of chemically extracted endotoxin, free endotoxin, and non-toxic material from Escherichia coli $078 \mathrm{~K} 80$

LD 50, ED 50 and $\mathrm{FI}_{4} 0$ (the amount of material giving an area of $40 \mathrm{~cm}^{2}$ under a fever curve) values were determined by the methods of Haskins et al. (196I).

Stage of purification

Ammonium sulphate precipitation

Preliminary Sephadex

G-100 chromatography

DEAE cellulose chromatography

Followed by

Sephadex G-100

chromatography

Purified phenol extracts

Purified ether extract

Fraction*
Crude
endotoxin II
SI. I
R
D I
D2
D I S I
$D_{2}$ S I
P I
P2

E
LD $50(\mu \mathrm{g}$. per mouse

370

$484 \cdot 2$

$>1000$

$>1000$

N.D.

$>600$

$24 \mathrm{I}$

595

N.D.

550
ED $50(\mu \mathrm{g}$.$) \quad FI 40(\mu \mathrm{g}$.

per mouse + per kg. (rabbit)

$\begin{array}{ll}0.016 & 17\end{array}$

O. I5O $\quad I 5.6$

N.D. $\dagger \quad$ N.D.

$0.070>600$

0.014 N.D.

$0.007 \quad>6.25 \times 10^{3}$

$0.004 \quad 9.5$

$0.100 \quad$ II

$0.320 \quad 20 \cdot 7$

$0.040 \quad 19$

* All fractions are as in Fig. I, other than P I and P 2 which were purified fractions of a phenol+ water extract and $\mathrm{E}$ which was a pure aqueous ether extract from Escherichia coli $078 \mathrm{~K} 80$.

$\uparrow$ Not determined.

ED 50 is the amount of material protecting $50 \%$ of mice in a group.

\section{Table 2. Local Shwartzman reactions produced by purified free endotoxin (fraction D2 $S_{I}$ )}

Groups of five mice were injected intradermally with the sensitizing dose and challenged intravenously $18 \mathrm{hr}$ later with $50 \mu \mathrm{g}$. of fraction $\mathrm{D}_{2} \mathrm{~S}$. Results were read on the inner skin surface $8 \mathrm{hr}$ later.

$$
\begin{array}{cc}
\begin{array}{c}
\text { Sensitizing dose } \\
(\mu \mathrm{g} .)
\end{array} & \begin{array}{c}
\text { Reaction to challenge* } \\
\text { (50 } \mu \mathrm{g} . \text { of D } 2 \text { S I intravenously) }
\end{array} \\
\text { 10 } & 2 \pm, 3- \\
20 & 2+, 3 \pm \\
40 & 5+
\end{array}
$$

* No. of mice reacting and extent of reaction: $--=$ positive; $\pm=$ weak positive; $-=$ negative.

Shwartzman reactions. Fraction D2Si (pure free endotoxin) was tested. (a) Local. A haemorrhagic lesion developed at the site of the primary injection. Results are shown in Table 2. (b) General. Death occurred almost immediately on challenge when both the primary and challenge injections were greater than $4 \mathrm{mg}$./mouse. Smaller doses resulted in a severe spasm followed by death within $\mathrm{I} 2 \mathrm{hr}$; the least amount producing this effect was $2 \mathrm{mg}$./mouse for both primary and challenge doses. In shocked animals, 
kidney damage and exudation of blood into the peritoneum was observed. Far larger amounts of endotoxin were required to elicit these reactions than were required to produce other effects of endotoxin, such as pyrogenicity or non-specific protection against infection.

Serological relationships between endotoxins and the non-toxic material. Hyperimmunization of rabbits with repeated subcutaneous injections of crude endotoxin II fraction (Fig. I) yielded an antiserum giving precipitin lines with all samples of endotoxin prepared from Escherichia coli $078 \mathrm{~K} 80$ whether extracted from bacteria or isolated from culture fluids. This antiserum, however, did not react with the nontoxic material. Nor did this latter material stimulate the production of precipitating antibodies in rabbits and in this respect it resembled the hapten described by Anacker et al. (1964) and Rudbach et al. (1967). All the endotoxin fractions, and the nontoxic material gave a common precipitin line with antisera prepared by hyperimmunization of rabbits and horses with whole bacterial cells. A multiplicity of precipitin lines was produced against rabbit antiserum, but against antiserum prepared in horses only a single line was observed. This single precipitin line between hyperimmune horse antiserum and endotoxin is almost type specific for $E$. coli strains. Horse antiserum prepared against whole bacteria of five common animal enteropathogens gave a clear preciptin line against endotoxin derived from the immunising serotype. At low concentration the reaction was fully specific and has been used as a basis for the assay of endotoxin from a known serotype for which horse antiserum was available.

Stability of free endotoxin. Endotoxins are so toxic that it is not possible to inject them in other than very small amounts to invoke immunity either against themselves or against the organism from which they were derived. Attempts were made to detoxify free endotoxin, the extent of detoxification being assessed by the loss of ability to cause hypothermia and diarrhoea in mice. Endotoxin proved resistant to exposure at $100^{\circ}$ for $60 \mathrm{~min}$. at $\mathrm{pH} 7.5$ and it also resisted $0.5 \%$ neutral formalin for $30 \mathrm{~min}$, at $100^{\circ}$ and 8 weeks at $37^{\circ}$. It was unaffected by freezing and thawing from $-70^{\circ}$ to $50^{\circ}$ fifty times. Hydrolysis by $\mathrm{N}$-hydrochloric acid at $100^{\circ}$ abolished toxicity and antigenicity.

Kim \& Watson (1964), and Badakhsh \& Foster (1966) reported the detoxification of chemically-extracted endotoxin with papain and lysoyzme, respectively. We were unable to detoxify free endotoxin with lysozyme. Equally inactive were: $\beta$-glucosidase, $\beta$-galactosidase, cellulase, $\beta$-amylase, Mylase-P (a mixture of carbohydrases from Aspergillus oryzae), chymotrypsin, trypsin, pepsin and chitinase. Free endotoxin was subjected to high voltage paper electrophoresis (Gross, I96I) after treatment with lysozyme and chitinase. No free carbohydrates could be found after this treatment.

\section{DISCUSSION}

Although endotoxin extracted chemically from whole bacteria has been extensively studied, little is known about endotoxins found free in culture fluids. Shear \& Turner (1943) studied the tumour-necrotizing ability of their cell-free endotoxic lipopolysaccharide. Todd, Shaw, Blain \& Boyle (1958), showed that bacteria grown in inorganic media liberated endotoxin into the culture fluid and, Taylor, Knox \& Work (1966) showed that a lipopolysaccharide endotoxin was released into cultures by a lysine-requiring mutant of Escherichia coli. Our own results showed that in aerated 
liquid cultures of $E$. coli $078 \mathrm{~K} 80$, large amounts of endotoxin were liberated into the culture fluid, together with a non-toxic entity which could be separated on DEAE cellulose and purified using Sephadex G-I00 (Marsh \& Crutchley, 1967). The origin of these substances in culture fluids is uncertain, but it seems unlikely that they result from leaching or lysis of the bacteria during growth. Taylor et al. (1966) showed that their lipopolysaccharide was excreted by a rough lysine-dependent mutant when lysine was deficient in the medium, whereas the $E$. coli $078 \mathrm{~K} 80$ (used in the present work) was a smooth ovine enteropathogen without any unusual requirements. As Taylor et al. (1966) found, the endotoxin in the culture fluid appeared to be derived by excretion from the bacteria rather than by lysis or leaching. The non-toxic fraction probably arose similarly, although its relation to endotoxin is not yet established (Marsh \& Crutchley, 1967). The purified free endotoxin separated from culture fluids of $E$. coli $078 \mathrm{~K} 80$ possess all the properties of endotoxin extracted from the bacteria by chemical procedures.

The non-toxic low molecular weight material (Fraction DISI) has some properties in common with the hapten (native protoplasmic polysaccharide) described by Anacker et al. (1964) and Rudbach et al. (1967). Apart from its ability to induce resistance to Salmonella typhi infection in mice (and to act as an adjuvant for diptheria and tetanus toxoids; P. Knight, personal communication) properties not shared by native hapten (native protoplasmic polysaccharide) it has none of the biological properties of endotoxin.

While neither the non-toxic preparation nor native hapten (Anacker et al. 1964) stimulated the formation of precipitating antibodies in rabbits, the non-toxic material, unlike native hapten, gave precipitin lines against horse and rabbit antisera prepared by immunisation of animals with whole bacteria. This suggests that the non-toxic material is combined in the organism with substances which may allow it to act as an antigenic determinant. These differences may be a reflection of the mild methods used in preparing the non-toxic material as compared with the vigorous methods employed by Anacker et al. (1964) and Rudbach et al. (1967). There may be a relationship between our non-toxic material, native hapten, and other low molecular weight isolates such as the acidic polysaccharides described by Westphal et al. (I964). These seem to possess both some of the properties of endotoxin and of native hapten.

We thank Mr B. Shaw (Veterinary Investigation Centre, Newcastle) for providing Escherichia coli $078 \mathrm{~K} 80$, and Dr S. R. M. Bushby for help with tumour necrosis experiments. We are indebted to Dr M. P. Sterne for advice and helpful discussions.

\section{REFERENCES}

Anacker, R. L., Finklestein, R. A., Haskins, W. T., Landy, M., Milner, K. C., Ribi, E. \& STASHAK, P. W. (1964). Origin and properties of naturally occurring hapten from Escherichia coli. J. Bact. 88, 1705 .

Badakhsh, F. F. \& Foster, J. W. (1966). Detoxification and immunogenic properties of endotoxincontaining precipitate from Brucella abortus. J. Bact. 9ז, 494.

Boivin, A. \& Mesrobeanu, L. (1933). Contribution á l'étude de la composition chimique des bactéries. Substances azotées et phosphorées 'acido-solubles'. C.r. séanc. Soc. Biol. 112, 76.

Crutchley, M. J., Marsh, D. G. \& Cameron, J. (I967). Free endotoxin. Nature, Lond. $214,1052$. Gross, D. (196I). An apparatus for high voltage paper electrophoresis. J. Chromat. 5, 194. 
Haskins, W. T., LANDy, M., Milner, K. C. \& RiBi, E. (196I). Biological properties of parent endotoxins and lipoid fractions with a kinetic study of acid-hydrolysed endotoxin. J. exp. Med. II4, 665.

HommA, J. Y. (1952). The Shwartzman phenomenon in the mouse. Jap. J. exp. Med. 22 , I7.

KIM, Y. B. \& WATSON, D. W. (I964). Inactivation of Gram-negative bacterial endotoxins by papain. Proc. Soc. exp. Biol. Med. I15, I40.

Marsh, D. G. \& CRUTChley, M. J. (I967). Purification and physico-chemical analysis of fractions from the culture supernatant of Escherichia coli $078 \mathrm{~K} 80$ : Free endotoxin and a non-toxic fraction. J. gen. Microbiol. 47, 405.

OlITZKI, L., Avinery, SH. \& Koch, P. K. (1942). The hypothermic and adreno-haemorrhagic effects of bacterial vaccines. J. Immun. 45, 237.

OUChTERLONY, O. (I949). Antigen-antibody reactions in gels. Acta path. microbiol. scand. $26,507$.

ReED, L. J. \& MUENCH, H. (1938). A simple method of determining fifty per cent endpoints. Am. J. Hyg. 27, 493.

Ribi, E., Haskins, W. T., Landy, M. \& Milner, K. C. (I96i). Preparation and host-reactive preperties of endotoxin with low content of nitrogen and lipid. J. exp. Med. r14, 647 .

RobertS, R. S. (1966). Preparation of endotoxin. Nature, Lond. 209, 80.

RowLEY, D. J. (I955). Stimulation of natural immunity to Escherichia coli. Lancet I, 232.

Rudbach, J. A., Anacker, R. L., Haskins, W. T., Milner, K. C. \& Ribi, E. (1967). Physical structure of a native protoplasmic polysaccharide from Escherichia coli. J. Immun. 98, r.

SHEAR, M. J. \& TURner, F. C. (I943). Chemical treatment of tumours V. Isolation of the haemorrhage producing fraction from Serratia marcescens. (Bacillus prodigiosus) culture filtrates. J. natn. Cancer Inst. 4, 8I.

Taylor, Alina, KNox, K. W. \& Work, Elizabeth (I966). Chemical and biological properties of an extracellular lipopolysaccharide from Escherichia coli grown under lysine limiting conditions. Biochem. J. 99, 53.

Todd, J. P., Shaw, J. A. M., Blain, J. A. \& Boyle, W. (1958). The isolation and comparison of pyrogenic factors from Proteus vulgaris. J. Pharm. Pharmac. 1o, 223T.

WestPhal, O., Lüderitz, O., EICHENBERGER, E. \& KeIDERLING, W. (I952). Über bakterielle Reizstoffe. I. Mitt: Reindarstellung eines Polysaccharid-Pyrogens aus Bacterium coli. Z. Naturf. 7 b, 536.

WestPhal, O., Beckmann, Ilse, Hämmerling, U., Jann, Barbara, Jann, K. \& Lüderitz, O. (I964). Recent investigations on the polysaccharide component of enterobacterial endotoxins ( $\mathbf{S}$ and $\mathbf{R}$ forms). In Bacterial Endotoxins ed. by M. Landy \& W. Braun, p. I. Institute of Microbiology Rutgers University Press. 